\title{
A novel model of humin
}

\author{
É. Lichtfouse
}

Laboratoire Sols et Environnement, INRA/ENSAIA-INPL, 2 avenue de la Forêt de Haye, 54505 Vandouvre-Lès-Nancy, France

Our poor knowledge of the structure and formation of humic substances stems from the lack of suitable tools which enable the study of the molecular structure of these complex, yellowbrownish materials. Here, several findings using a combination of isotopic, pyrolytic, microscopic and gas chromatographic methods lead to the proposal of a novel model of humin structure. The formation of humin should thus involve at least three processes: selective preservation of microbial, straight-chain biopolymers; physical encapsulation of apolar substances by weak forces; and chemical binding by covalent bonds.

\section{Unexpected ${ }^{13} \mathrm{C} /{ }^{12} \mathrm{C}$ ratios}

In 1995, while analysing various plant and crop soil materials, we were surprised to find out that soil humus is often enriched in carbon 13 relative to plant matter [1]. This was rather unexpected because the intense biodegradation of plant debris in soils should have led to the selective preservation of the most resistant, ${ }^{13} \mathrm{C}$-depleted lignin and lipid parts of the plant. We therefore proposed two alternative explanations for the occurrence of ${ }^{13} \mathrm{C}$-enriched humus. First, our results fit well with the recondensation mechanism involving condensation of small molecules such as amino acids and sugars [2], which are indeed ${ }^{13} \mathrm{C}$-enriched relative to the bulk plant carbon. A such pathway has been nicely evidenced in 1917 by Maillard who compared synthetic and natural humic substances [2]. Second, since highly resistant, aliphatic biopolymers have been recently discovered in microbes and sediments [3], we suspected the occurrence of such biopolymers in soils. Indeed, soil microbes feeding on ${ }^{13} \mathrm{C}$-enriched amino acids and sugars should biosynthesise ${ }^{13} \mathrm{C}$-enriched biopolymers. Therefore, several analytical means were used to probe for such aliphatic biopolymers in soils, as described below.

\section{Resistant straight-chain biopolymers}

In order to test the biopolymer hypothesis, we watched carefully a sample of HF-treated humin by transmission electron microscopy. Resistant aliphatic biopolymer showing typical very thin laminae (25 $\mu \mathrm{m}$ thick) were indeed present [4], thus strengthening the biopolymer hypothesis. Further pyrolysis of humin followed by gas chromatography coupled to mass spectrometry (GC-MS) revealed the occurrence of $\mathrm{C}_{11}-\mathrm{C}_{24}$ linear alkanes and alkene doublets $[5,6]$ which are typical breakdown products of aliphatic biopolymers [3]. Therefore, a part of soil organic matter is indeed composed of straight-chain biopolymers (Fig. 1).

\section{Encapsulated plant wax alkanes}

On the other hand, we were puzzled by the additional occurrence in the humin pyrolysate of long-chain $\mathrm{C}_{27}-\mathrm{C}_{33}$ linear alkanes with the typical plant wax fingerprint [5]. Indeed, since such compounds are not formed by pyrolytic cleavage, and since they are still present in the pyrolysate despite preextraction of the soil sample and of the humin, they must somehow have been encapsulated in the humin matrix by

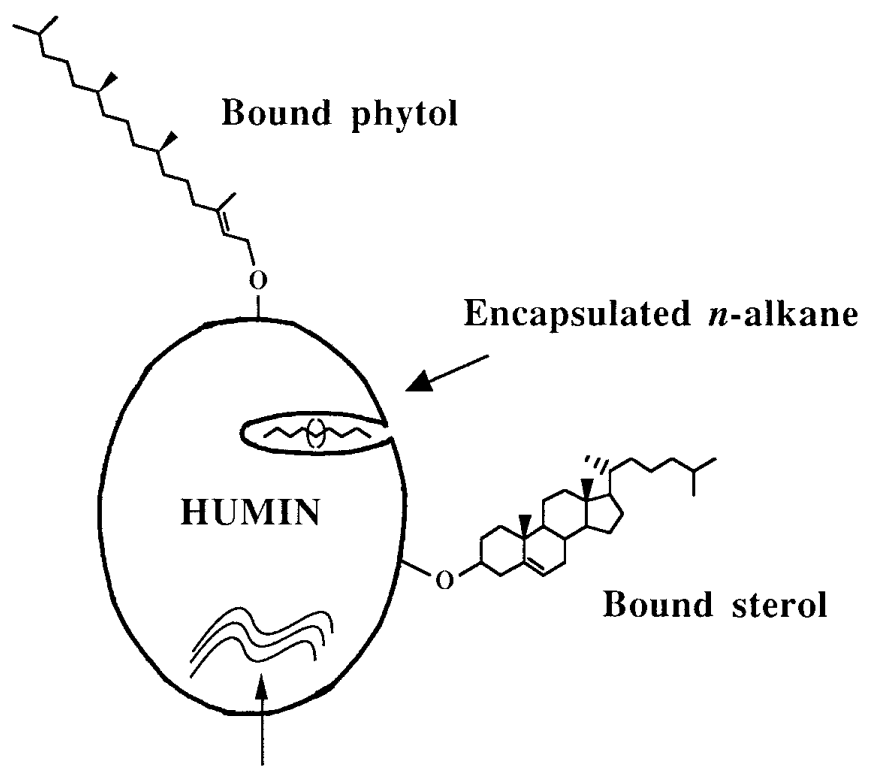

Resistant aliphatic biopolymer

Figure 1. Model of humin explaining the stabilization of soil organic matter 1) by encapsulation of small polar molecules (physical sequestration), 2) by binding of functionalized biomarkers (chemical sequestration), and 3 ) by selective preservation of aliphatic biopolymers. 
non-covalent bonds [7]. However, to confirm this hypothesis, we had to find another way to distinguish "free" soilextractable substances [8,9] from their humin-bound counterparts. At this point, we thought that trapped molecules should be older than their free counterparts because encapsulation should induce the temporary storage of organic substances. Having previously set up a way to calculate the relative age and turnover of soil molecules by maize labelling $[9,10]$, we measured the ${ }^{13} \mathrm{C} /{ }^{12} \mathrm{C}$ ratio of plant-derived $\mathrm{C}_{27}-\mathrm{C}_{33}$ linear alkanes both from the soil extract and from the humin pyrolysate. As predicted, the isotopic composition were significantly different, yielding for example $\delta^{13} \mathrm{C}$ values [11] of $-28.1 \%$ or the free $\mathrm{C}_{31}$ alkane and $-29.7 \%$ o for the humin-bound homologue [7]. A such difference means that the bound substance is 7 years older than the free substance. These findings clearly demonstrate that apolar organic molecules can be trapped by weak bonds into the humin matrix. Nonetheless, other molecules may also be trapped by strong, covalent bonds, as discussed below.

\section{Biomarkers in humin}

Gas chromatography-mass spectrometric analysis of the humin pyrolysate revealed the occurrence of hopanoid and steroid biomarkers [6]. Biomarkers have been widely used to assess the biological sources of dead matter [12]. Here, we found pristene, sterenes, and hopenes in the humin pyrolysate [6]. Pristene is most likely derived from the phytol side chain of chlorophyll. Pristene is thus a marker of photosynthetic activity. Precursors of sterenes include $\mathrm{C}_{27}$ algal and $\mathrm{C}_{29}$ plant sterols. Hopenes are mainly inherited from bacterial hopanols [13]. Since all those alkenes are products of pyrolytic cleavage, alcohols were most likely linked to humin by ester binding. This finding is in good agreement with the recent studies of the Hamburg group, nicely evidencing the occurrence of ester-bound xenobiotics by $\mathrm{Na}^{18} \mathrm{OH}$ cleavage of humic compounds [14].

\section{Conclusion}

Three processes of humin formation have been assessed using molecular, isotopic and microscopic tools: 1) the selective preservation of microbial, straight-chain biopolymers, 2) the physical encapsulation of apolar substances by weak forces, and 3) the chemical binding by covalent bonds. Noteworthy, the structures of the molecules shown on the model (Fig. 1) have been unambiguously identified. Moreover, the model does not show links between two or more molecules because, to my best knowledge, such structures have not been identified. Further work at the molecular level is in progress to unravel the humic puzzle. Specifically, the knowledge of bonding forces occurring in humic substances is a prerequiste to understand the fate of xenobiotics in soils, waters and sediments [15].

\section{References}

1. Lichtfouse, E.; Dou, S.; Girardin, C.; Grably, M.; Balesdent, J.; Behar, F.; Vandenbroucke, M. Org. Geochem. 1995, 23, 865-868.

2. Maillard, L. C. Ann. Chim. Paris 1916, 5, 258-317. Maillard, L. C. An. Chim. Paris 1917, 7, 113-152.

3. Tegelaar, E. W.; De Leeuw, J. W.; Derenne, S.; Largeau, C. Geochim. Cosmochim. Acta 1989, 53, 3103-3106. Derenne, S.; Largeau, C.; Casadevall, E.; Berkaloff, C.; Rousseau, B. Geochim. Cosmochim. Acta 1991, 55, 1041-1050.

4. Lichtfouse, E.; Chenu, C.; Baudin, F. Org. Geochem. 1996, 25, 263-265.

5. Lichtfouse, E.; Chenu, C.; Baudin, F.; Leblond, C.; Da Silva, M.; Behar, F.; Derenne, S.; Largeau, C.; Wehrung, P.; Albrecht, P. Org. Geochem. 1998, 28, 411-415.

6. Lichtfouse, E.; Leblond, C.; Da Silva, M.; Behar, F. Naturwissenschaft 1998, 85, 497-501.

7. Lichtfouse, E.; Wehrung, P.; Albrecht, P. Naturwissenschaft 1998, 85, 449-452.

8. Lichtfouse, E.; Bardoux, G.; Mariotti, A.; Balesdent, J.; Ballentine, D. C.; Macko, S. A. Geochim. Cosmochim. Acta 1997, 61, 1891-1898. Lichtfouse, E.; Budzinski, H.; Garrigues, P.; Eglinton, T.I. Org. Geochem. 1997, 26, 535-359. Lichtfouse, E. Naturwissenschaft 1998, 85, 76-77.

9. Lichtfouse, E. Naturwissenschaft 1997, 84, 23-25.

10. Lichtfouse, E. Tetrahedron Lett. 1995, 36, 529-530. Lichtfouse, E.; Budzinski, H. Analusis 1995, 23, 364-369.

11. Isotopic compositions are expressed in per mil as $\delta^{13} \mathrm{C}$ values relative to the Pee Dee Belemnite standard: $\delta^{13} \mathrm{C}=$ $\left[\left({ }^{13} \mathrm{C} /{ }^{12} \mathrm{Csample}-{ }^{13} \mathrm{C} /{ }^{12} \mathrm{Cstd}\right) /\left({ }^{13} \mathrm{C} /{ }^{12} \mathrm{Cstd}\right)\right] \times 10^{3}$.

12. Albrecht, P.; Ourisson, G. Angew. Chem. Internat. Edit. 1971, 10, 209-286. Eglinton, G. Pure Appl. Chem. 1973, 34, 611632.

13. Ourisson, G.; Albrecht, P. Acc. Chem. Res. 1992, 25, 398-402.

14. Richnow, H. H.; Seifert, R.; Hefter, J.; Kästner, M.; Mahro, B.; Michaelis, W. Org. Geochem. 1994, 22, 671-681. Richnow, H. H.; Seifert, R.; Hefter, J.; Link, M.; Francke, W.; Schaefer, G.; Michaelis, W. Org. Geochem. 1997, 26, 745-758.

15. Lichtfouse, E. Analusis 1997, 25, 16-23. 